TP Periodica Polytechnica Electrical Engineering and Computer Science

59(3), pp. 70-77, 2015

DOI: $10.3311 /$ PPee. 8585

Creative Commons Attribution (i)

RESEARCH ARTICLE

\section{The Contribution of Conductor Temperature and Sag Monitoring to Increased Ampacities of Overhead Lines (OHLs)}

Viktor Lovrenčić ${ }^{1 *}$, Marko Gabrovšek ${ }^{1}$, Matej Kovač ${ }^{1}$, Nenad Gubeljak ${ }^{2}$, Zdravko Šojat ${ }^{3}$, Zaviša Klobas ${ }^{3}$

Received 17 May 2015; accepted after revision 21 August 2015

\begin{abstract}
The electric utility industry is restructuring itself to operate in a competitive wholesale market. However, the transmission system remains a regulated entity that connects deregulated generation with the end consumer. In many countries, the pace of investment in OHLs has lagged behind the rate of load growth and generated additional capacities, due to public, regulatory, environmental and financial obstacles to the construction of new transmission facilities. Consequently, many OHLs reached critical values of ampacity and sag. Many renewable energy sources, especially hydro plants, solar or wind farms also require dynamic operation of the power grid. OTLM Overhead Transmission Line Monitoring system is adding new dimensions to the operation of OHLs enables more efficient performance while at the same time enhances the safety of system operation. A maximum utilization of the OHL ampacity is only possible, if the operators have accurate data about the actual ground clearance, crossed lines, vegetation, instantaneous conductor temperature and current.

With the measurements captured and processed by OTLM, the operator of the transmission network can optimize and determine the operation mode of OHLs. Software solutions also provide the means for a short-term prediction of conductor temperature. Temperature data along with data gained by laser scanning or similar measurements and diagnostics of the OHLs is necessary to up-rate OHL projects. This paper is supported with case studies, which prove that temperature and sag monitoring is an essential part of the transmission smart-grid.
\end{abstract}

\section{Keywords}

OHL, OHL monitoring, sag, dynamic thermal rating (DTR), ampacity

\footnotetext{
${ }^{1}$ C\&G d.o.o. Ljubljana, Riharjeva 38, 1000 Ljubljana, Slovenia

${ }^{2}$ Faculty of Mechanical Engineering, University of Maribor, Smetanova ulica 17, 2000 Maribor, Slovenia

${ }^{3}$ HOPS d.o.o., Croatian Transmission System Operator,

Kupska 4, 10000 Zagreb, Croatia

*Corresponding author, e-mail: viktor.lovrencic@c-g.si
}

\section{Introduction}

The future successful development of the transmission network, which is highly effected by the deregulation of the energy market, confronts network operators with new technologically demanding processes. Opening the energy market in Europe has changed the traditional understanding of the planned construction of production sources, when national economies preferred to be self-sufficient and imported only necessary quantities of electricity. Transmissions of electricity have changed immensely. In the last decades, traditional cross-border exchanges have greatly changed, because the electricity flow directions follow its market price. The current low price of renewable energy sources, especially wind, is suspending the production of conventional aggregates running on coal or even gas.

The electricity market therefore demands stable and reliable operation in new conditions with the support of smart-grid elements. The nature of renewable energy sources, especially wind, can cause dynamical load changes in transit lines. Direction of energy flow in power lines can change, therefore some lines are overloading, while others remain under designed load. On the other hand, local operators are under pressure due to incorporation of new renewable energy sources, but they cannot follow the reconstruction of weak lines and the construction of new lines after the construction of new renewable energy sources.

Due to frequent overloads of individual lines, new methods of ampacity monitoring are required. New maintenance concepts are not enough, since the stability and safety can be insured only if we know the present field conditions.

This is why the challenge is managing infrastructural linear facilities such as OHLs in real-time, while taking in to account changing energy flow and weather conditions along the OHL is really demanding and complex. Sag and consequently safety heights change due to elastic or plastic deformations, additional load ratings (especially in winter - ice) and we should not neglect that conductors are threatened by vegetation.

Determining the actual line geometry is a very useful support activity, which can be carried out with periodical LIDAR scanning to determine the exact sag, while taking in to account 
vegetation management and with real-time monitoring of conductor temperature and sag in the critical spans.

We implemented some successful projects, using data from the OTLM System, which supplies measurements of conductor temperature, sag and ampacity and builds and supports the smartgrid, which should comply with the following requirements [1]:

- Predictive - to avoid emergency situations,

- Capable of "self-tracking" - to correct and avoid the detected foreseeable problems,

- Interactive - with consumers and electricity market,

- Secure - against threats, risks.

The smart grid is characterized by increased grid observability with modern data integration and analytics to support advanced grid operations and control the power delivery chain integration and high-level utility strategic planning functions. Some key characteristics of an intelligent power grid are [1]:

- Grid equipment and assets are monitored by intelligent devices,

- Digital communication permits intelligent devices to communicate securely with utility enterprises,

- Data from the monitoring devices and other sources are consolidated to support the transformation of raw data into useful information through advanced analytics,

- Business intelligence and optimization tools provide advanced decision support at both automatic and human level.

A "roadmap" to an intelligent network includes the following steps [1]:

- Optimizing the electricity demand by managing peak consumption; electricity consumption control,

- Optimizing the supply of electricity by reducing losses in transmission networks,

- Optimizing the asset management by proactive maintenance, reducing interruptions and interventions during installations by workers,

- Optimizing the use of renewable energy.

\section{Increased sag caused by different mechanisms}

In the introduction we pointed out that sag control in conditions of dynamical line rating (DLR) is of high importance to safe operation.

Controlling sag dynamics is part of all construction and operational phases, from an excellent design, precise installation and sag control; it must be carried out periodically and at major events that cause additional load (ice), since the conductor stretches with age.

Sag control and knowing the actual catenary geometry of a certain span, safety heights and distances to junctions is safetywise extremely important (Fig. 1 and Fig. 2). This can be done with LIDAR or ground laser scanning or with sophisticated measuring devices (theodolites).
For example, analyses and exact data from airborne laser surveys show that increased sag, caused by different mechanisms of line degradation, including corrosion, wear, fatigue, chemical change and creep, leads to a decreasing ampacity of many OHLs (Fig. 1). In addition, OHL design clearance also does not take into account plastic strain, road construction, house erection and an increase of a cultural layer of the ground (Fig. 2) [1-3].

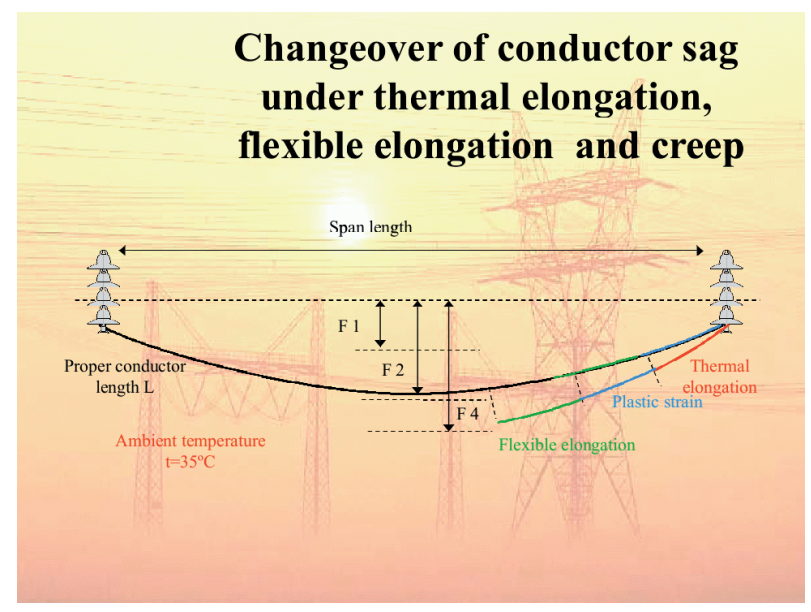

Fig. 1 Changeover of conductor sag

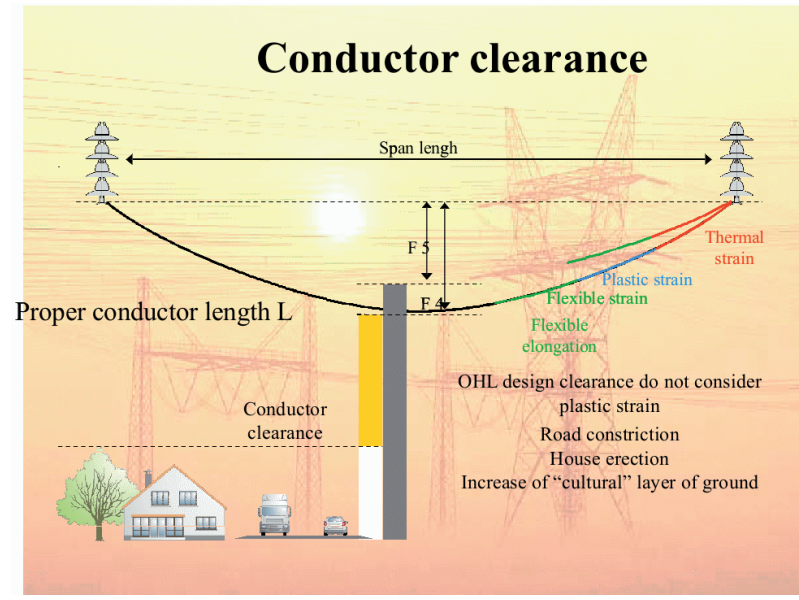

Fig. 2 Conductor clearance

Slovenian 110, 220, and 400kV transmission network has been fully scanned with an airborne laser, which gives the analysts, designers and maintenance workers a rich database. The documentation on the installation works and laser scans are of great help during the implementation of OTLM system on OHL. This data combined with the information from the operational and maintenance staff offers a qualitative basis for choosing measuring points to measure conductor temperature and weather station locations at critical spans, which are usually on important junctions (roads, railroads), critical sections with low safety heights and in silent valleys (no wind).

During the analysis of the pilot project "OTLM-DTR" on OHL 2x110kV Dravograd - Slovenj Gradec (Fig. 10 in 11), span SM23 - SM24, we gathered data on span geometry in various ways: [3-6]:

1. Design documentation (PLS-CADD) - installation. table, 
2. Additional calculation (PLS-CADD) - installation table,

3. Manual calculation: deterministic method (input daN),

4. Manual calculation: deterministic method (input N),

5. TLS (Terrestrial Laser Scanning) data,

6. DAMOS calculation with an IEEE formula (DTR),

7. Measurements with an ultrasound device,

8. Laser scanned data, gathered in GRID.MC,

9. Span control from the handover document C\&G-ELV.

While comparing the calculations we must be aware that input/output data can differ, because the calculation methodologies can be different, since they depend on the used technical regulations and standards during the construction of OHL and today (Table 1, 2 and 3).

Figures 3 and 4 depict the results (Tables 1 to 3), gathered with the TLS laser. The results are shown in AutoCAD format (on 26.4. - Blue, 25.7. - Red, and 29.7. - Green catenary).

The measurements on span SM23-SM24 have shown that we must carefully analyse the geometry of the actual catenary during installation "OTLM.DTR", since accurate temperature measurements and ambient data are of no help, if we do not know the actual sag. Sags can greatly differ from project data measurements or from last conducted measurements. In conductor temperature terms this difference can be as high as $10^{\circ} \mathrm{C}$, which is approximately $30 \mathrm{~cm}$ sag on the actual span.

\section{OTLM (Overhead Transmission Line Monitoring System)}

The OTLM device (Fig. 5) was developed to simultaneously measure temperature, sag and current of power lines. Temperature is measured directly - at sensor fixing points on the OHL phase conductor. The current transformer and the supplying unit provide the power supply for operation without any outside source of power. Housing is made of fire resistant composite material for heavy ambient conditions.

Measurements are transmitted to the control centre via available communication channels. The device is equipped with a GPS signal receiver. Temperature and current measurement is annotated by precise time stamp. The device enables local and remote access for meter settings, reading of current values, software updates, etc. Measurements and high-resolution events are transferred to selected computers and the control centre (SCADA) via standard IEC protocols (Fig. 6). Easy user access is available via a web browser (Fig. 7).

OTLM device installation is recommended during planned disconnections in close proximity of towers but after antivibration devices. In difficult terrain areas and highlands it is recommended that OTLM devices are installed in spans where the area changes sharply and conductors are shielded from wind by various natural or manmade barriers.

Optimally 3 to 4 OTLM devices should be installed in complex terrain areas. In flat woodless areas, the number of OTLM
Table 1 Sag analysis with different methods, date: 26.4 .2013 at 10.00a.m., OHL turned off, $\mathrm{I}=0 \mathrm{~A}$, ambient temperature $17.7^{\circ} \mathrm{C}$

\begin{tabular}{llll}
\hline Method & $\begin{array}{l}\text { Sag } \\
(\mathrm{m})\end{array}$ & $\begin{array}{l}\text { Ambient } \\
\text { temp. }\left({ }^{\circ} \mathrm{C}\right)\end{array}$ & $\begin{array}{l}\text { Safety } \\
\text { height }(\mathrm{m})\end{array}$ \\
\hline (1) Design doc. & 6.01 & 17.7 & 8.56 \\
(2) Installation table & 6.01 & 17.7 & 8.56 \\
(3) Manual calc. ${ }^{*}$ & 6.25 & 17.7 & 8.32 \\
(4) Manual calc. ${ }^{*}$ & 6.15 & 17.7 & 8.42 \\
(5) Laser TLS & 6.10 & 17.7 & 8.47 \\
(6) DAMOS & 6.08 & 17.7 & 8.49 \\
(7) Ultra-sound & 7.26 & 17.7 & 7.31 \\
(8) GRID.MC & 6.34 & N/A & 8.23 \\
(9) C\&G-ELV & 6.01 & 17.7 & 8.56 \\
\hline
\end{tabular}

Table 2 Sag analysis with different methods, date: 25.7 .2013 at 3.00p.m., OHL turned on, $\mathrm{I}=121$, ambient temperature $30^{\circ} \mathrm{C}$, conductor temperature $41.5^{\circ} \mathrm{C}$

\begin{tabular}{llll}
\hline Method & $\begin{array}{l}\text { Sag } \\
(\mathrm{m})\end{array}$ & $\begin{array}{l}\text { Ambient } \\
\text { temp. }\left({ }^{\circ} \mathrm{C}\right)\end{array}$ & $\begin{array}{l}\text { Safety } \\
\text { height }(\mathrm{m})\end{array}$ \\
\hline (1) Design doc. & 6.37 & 30 & 8.20 \\
(2) Installation table & 6.40 & 30 & 8.17 \\
(3) Manual calc.* & 6.40 & 30 & 8.17 \\
(4) Manual calc. $*$ & 6.30 & 30 & 8.27 \\
(5) Laser TLS & 6.62 & 30 & 7.95 \\
(6) DAMOS & 6.30 & 30 & 8.27 \\
\hline
\end{tabular}

Table 3 Sag analysis with different methods, date: 29.7.2013 at 2.30p.m., OHL turned on, $\mathrm{I}=135 \mathrm{~A}$, ambient temperature $35^{\circ} \mathrm{C}$, conductor temperature $44^{\circ} \mathrm{C}$

\begin{tabular}{llll}
\hline Method & $\begin{array}{l}\text { Sag } \\
(\mathrm{m})\end{array}$ & $\begin{array}{l}\text { Ambient } \\
\text { temp. }\left({ }^{\circ} \mathrm{C}\right)\end{array}$ & $\begin{array}{l}\text { Safety } \\
\text { height }(\mathrm{m})\end{array}$ \\
\hline (1) Design doc. & 6.52 & 35 & 8.05 \\
(2) Installation table & 6.55 & 35 & 8.02 \\
(3) Manual calc. ${ }^{*}$ & 6.46 & 35 & 8.11 \\
(4) Manual calc. $*$ & 6.36 & 35 & 8.21 \\
(5) Laser TLS & 6.76 & 35 & 7.81 \\
(6) DAMOS & 6.47 & 35 & 8.10 \\
\hline
\end{tabular}

* Manual calculations include only the influence of ambient temperature on sag (current, solar radiation, wind or other influences were not taken into account)

devices can be reduced to 2 devices at the beginning and end of the route or at the sections with considerable pivot angle. Realtime line temperature and current data at critical sectors help the operators to monitor the conditions.

When current critical values are exceeded, the operator is informed by an alarm. Alarms should be set to critical sag situations. This enhances the reliability, efficiency and safety of OHL operation. OTLM system supports real-time line rating operation. For example, wind farm production is usually curtailed due to static thermal rating of OHL. Using the OTLM system enables operation on real-time line rating of OHLs, which results in additional current ampacity. 


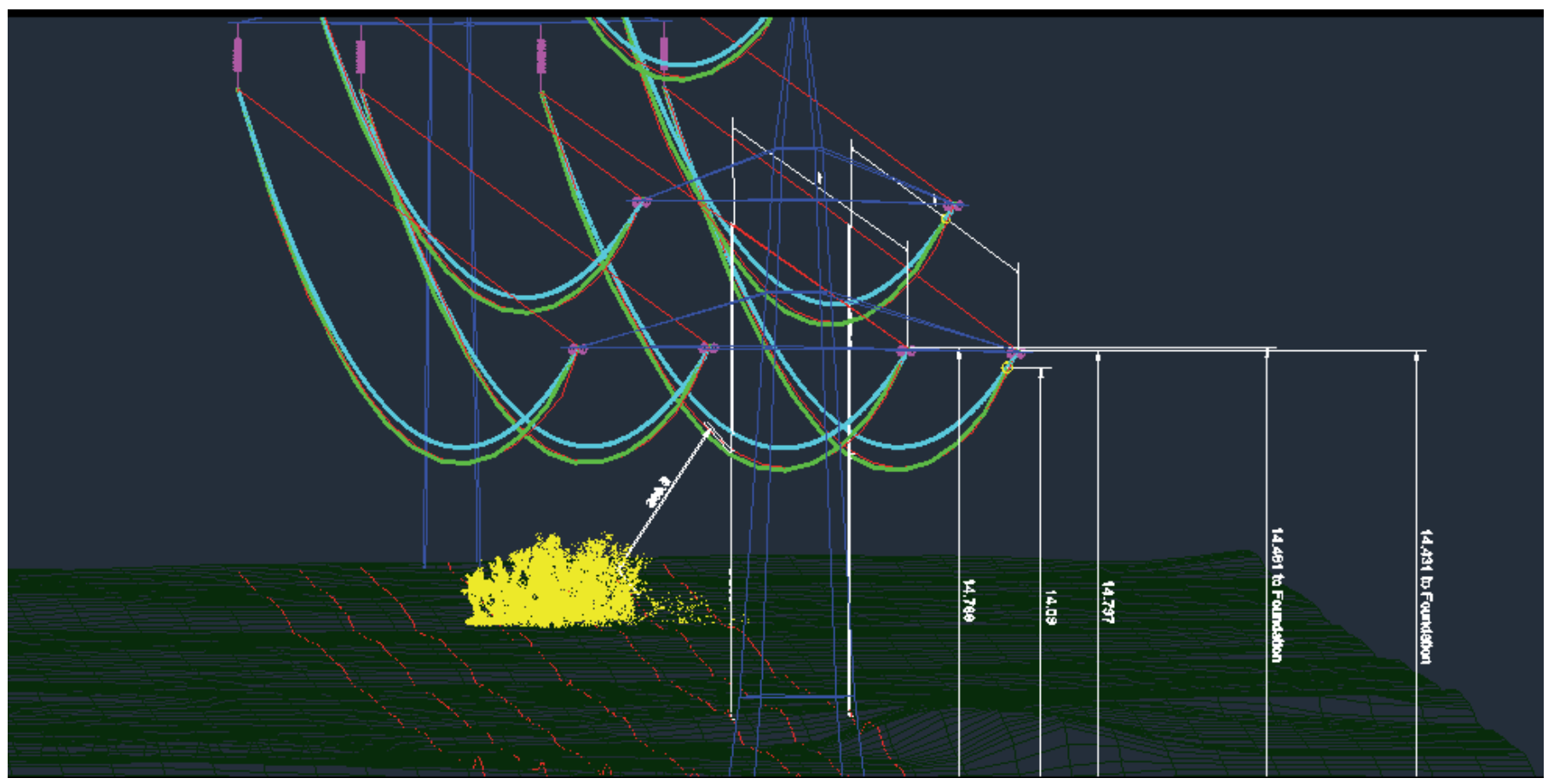

Fig. 3 Illustration of increased catenary sags due to higher ambient temperatures (Source: $C \& G$ )

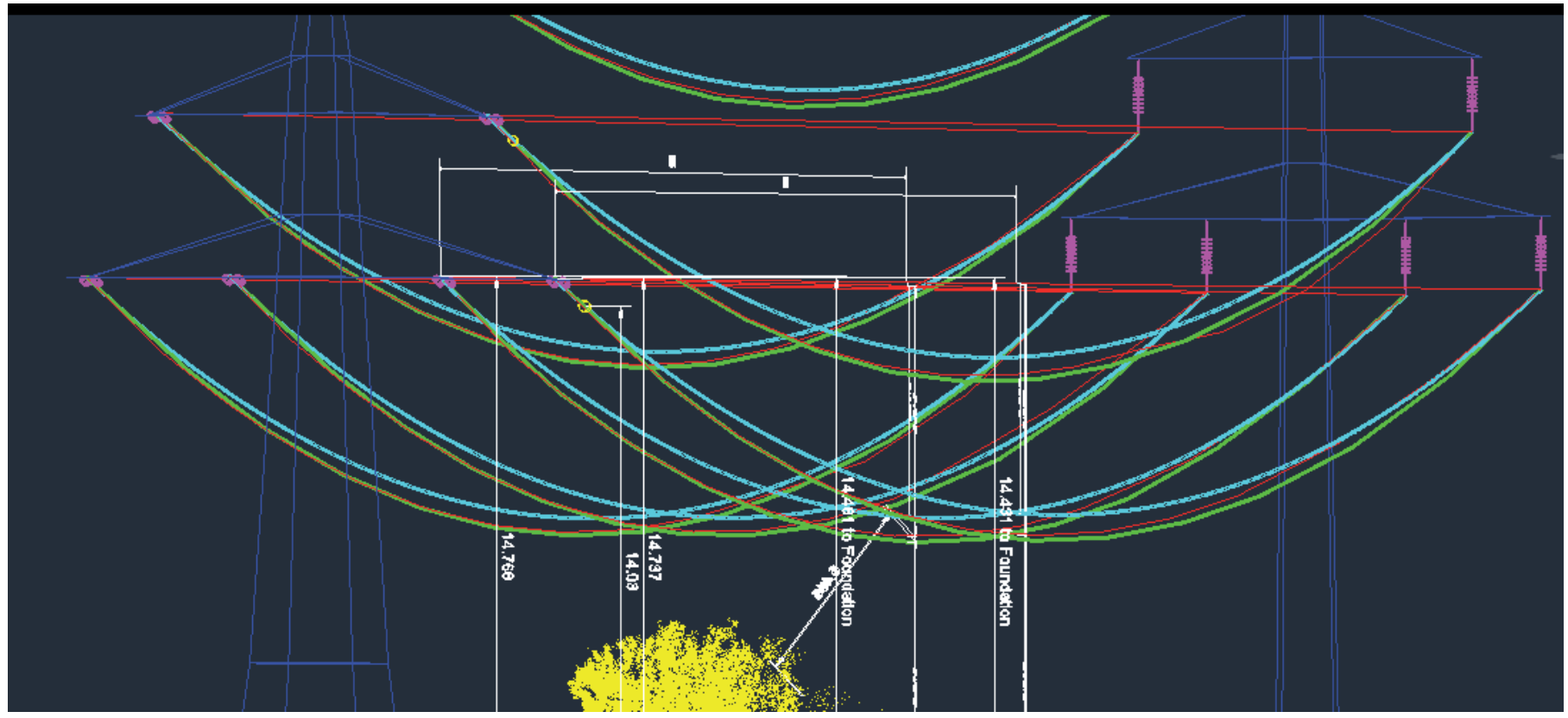

Fig. 4 Lateral illustration of increased sags due to higher ambient temperatures (Source: $C \& G$ )

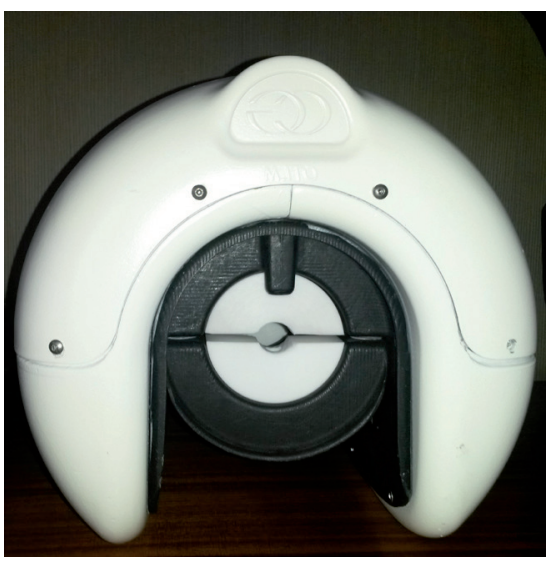

Fig. 5 OTLM device 


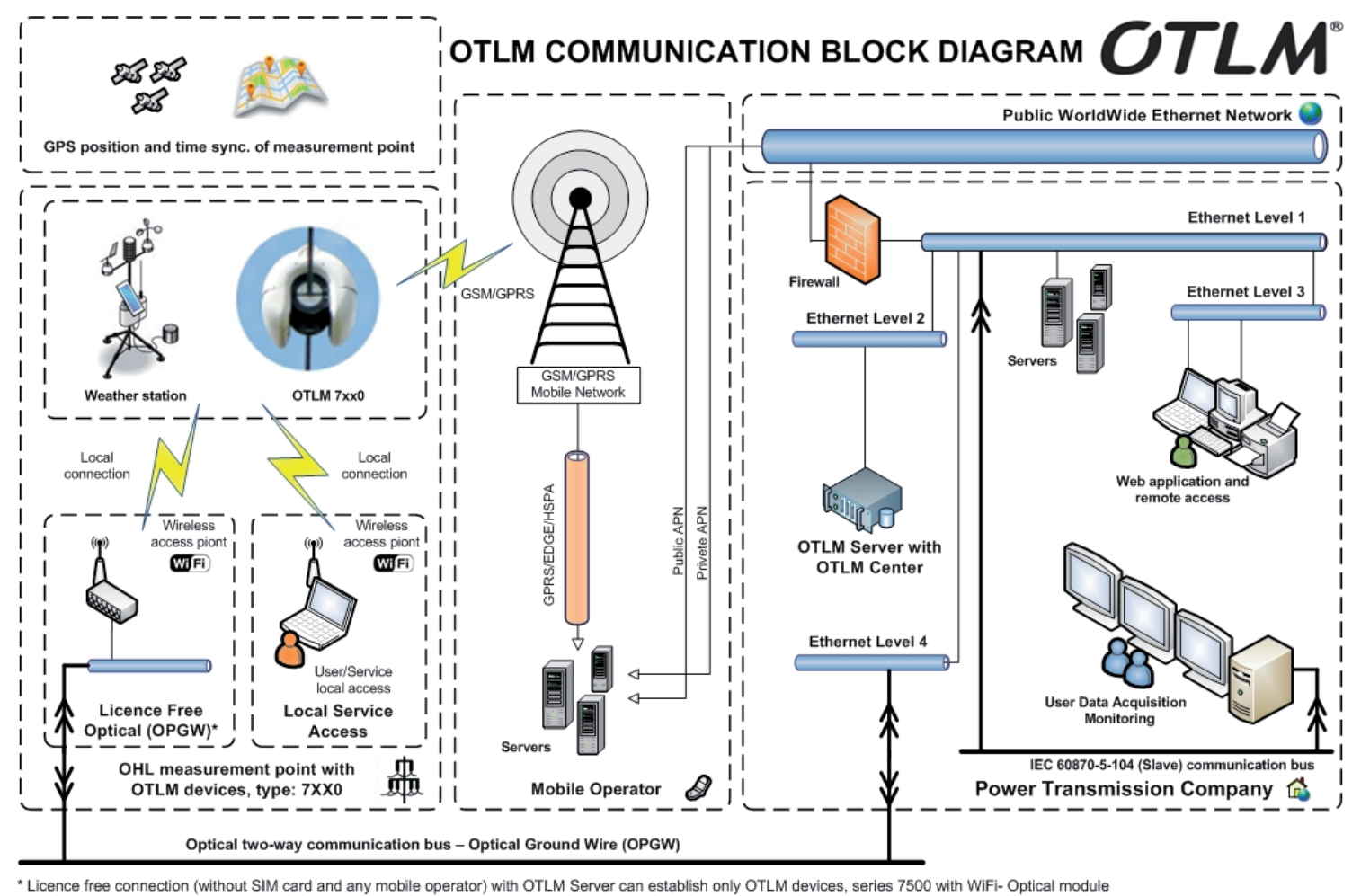

Fig. 6 OTLM Communication block diagram

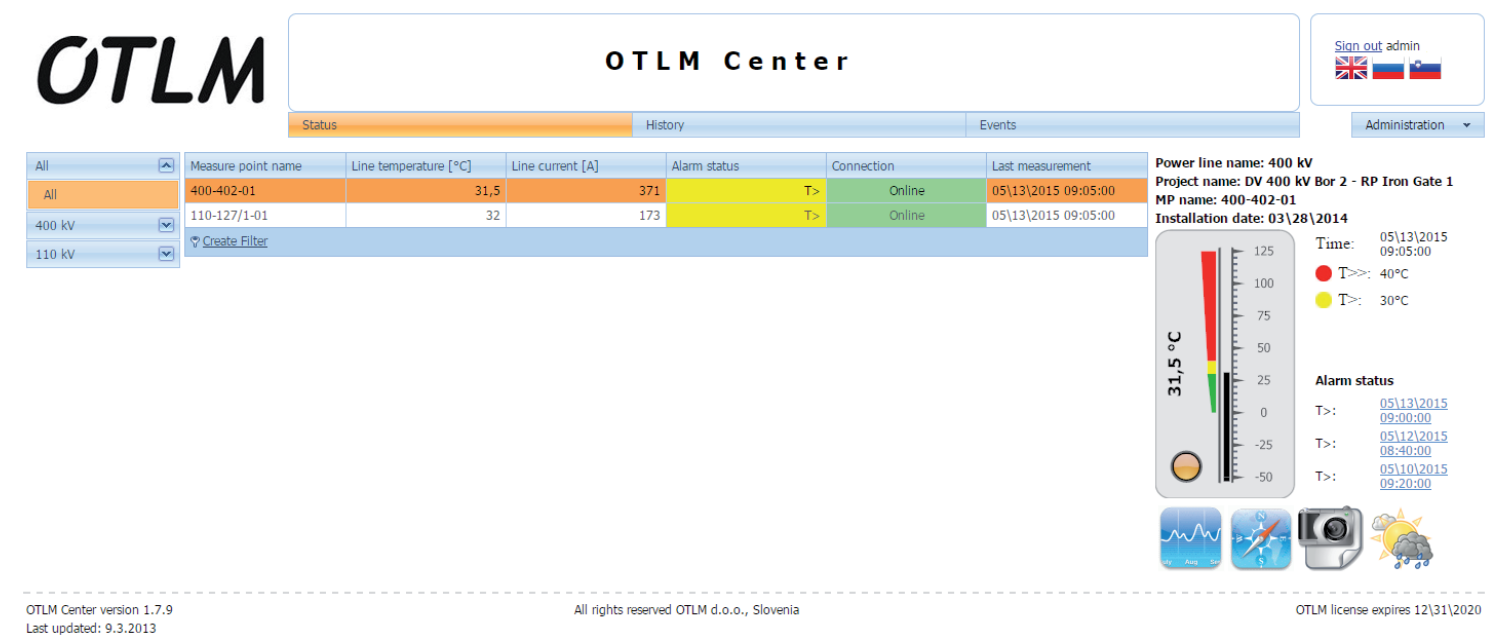

Fig. 7 OTLM Centre's platform

\section{OTLM Centre}

Based on our own experiences and requirements (expectations) of our customers, we have upgraded the basic concept of the OTLM System. The device features have progressed from conductor temperature measurements or STR (static thermal rating) and alarm states to OTLM Ampacity (if included weather prediction - DTR) calculation.

OTLM Centre with a built-in weather station, taking into account the newest CIGRE formula (TB 601) [7], enables the ampacity calculation. In combination with the measured conductor temperature and ambient conditions (weather station), we can calculate real-time sag and safety height with a mathematical model.

\subsection{OTLM - Ampacity (DTR)}

We have been actively monitoring and analysing the data from the pilot project "OTLM-DTR" on OHL $2 \times 110 \mathrm{kV}$ Dravograd - Slovenj Gradec, span SM23 - SM24 for several years. ELES has built in several DTR technologies on OHL, which enable analyses of STR and DTR data. The data is available from the year 2012 and this enables the developers to carry out comparison analyses and system improvements.

During this period we carried out calculations (DTR) with indirect methods (mathematical model), t.i. measurements with only ambient data, and with a direct method (conductor measurement method) with ambient data taken into account. We had at our disposal published empirical formulas CIGRE [7-12], IEC [13] and IEEE [14-16]. 
To determine the conductor current we decided to use the latest CIGRE [7] formula with ambient data and we additionally built in an "anchor" or measured conductor temperature data. We are sure that in this way we came close to the actual real-time physical conditions of the conductor and therefore we can assure a more reliable calculation of the existing DTR/DLR or ampacity. The same applies to the indirect method, in which numerous factors (constant factors and parameters, conductor aging or the actual state of conductor surface, absorption, radiation, etc.) influence the tolerance area.

We have to emphasise that today some transmission companies operate based on long-term operator experiences. To prevent overloads or conductor overheating they use overcurrent protection, which turns off conductors when they reach critical loads. Their only progress is that they set currents seasonally (winter, summer). Only some companies actively run networks with the support of DTR/DLR features.

The OTLM device offers big progress with its alarms (yellow, red), which give operators real-time temperature growth trends and in this way warns operators to discharge the relevant conductor. It therefore offers the operator more data than STR.

The reason why we call this a STR + function is because the input data is measured conductor temperature and measured ambient conditions and it takes into account the effects of current, conductor technical data, solar radiation and wind (speed, direction).

Very good example of possible overload is the case of OHL $110 \mathrm{kV}$ Crikvenica - Vrataruša, built in year 1960, with conductor diameter $240 \mathrm{~mm} 2$, located on the coast of the Adriatic Sea (Fig. 8). In 2010, in addition to HPP Senj ( 2 x 70MW on $110 \mathrm{kV}$ $+1 \times 70 \mathrm{MW}$ on $220 \mathrm{kV})$, a wind power plant $(14 \times 3 \mathrm{MW}=$ $42 \mathrm{MW}$ ) was additionally connected to this OHL, which represents a certain risk for this OHL operation $[17,18]$.

One branch leads to the transformer station Crikvenica and subsequently to the hydro plant Vinodol and the other to the hydro plant Senj. Since the wind power plant is located between HPP Vinodol and HPP Senj, it inevitability influences their operation. A major part of the current problems is connected to the energy placement, especially in the hydro-abundant periods, when this line is overloaded with energy from the south hydro plants and with no additional energy input from the wind power plant $[17,18]$.

This will continue to be a problem until the $110 \mathrm{kV}$ network is reinforced, especially if the HPP power output will increase to the planned $66 \mathrm{MW}$.

Figure 9 shows alarm states or STR+ on OHL, which was built in 1960 and has been constructed for $40^{\circ} \mathrm{C}$ conductor temperature. The OTLM device notified the operator that during the observation period the temperatures exceeded $50{ }^{\circ} \mathrm{C}$.

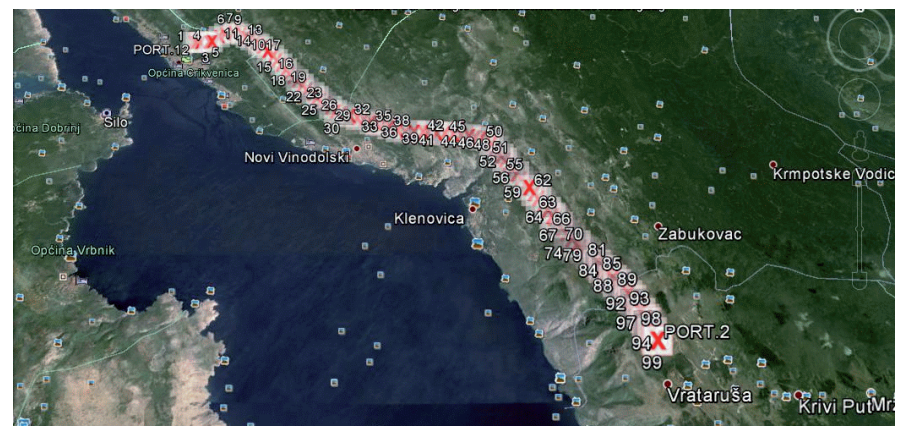

Fig. 8 OHL located by the sea

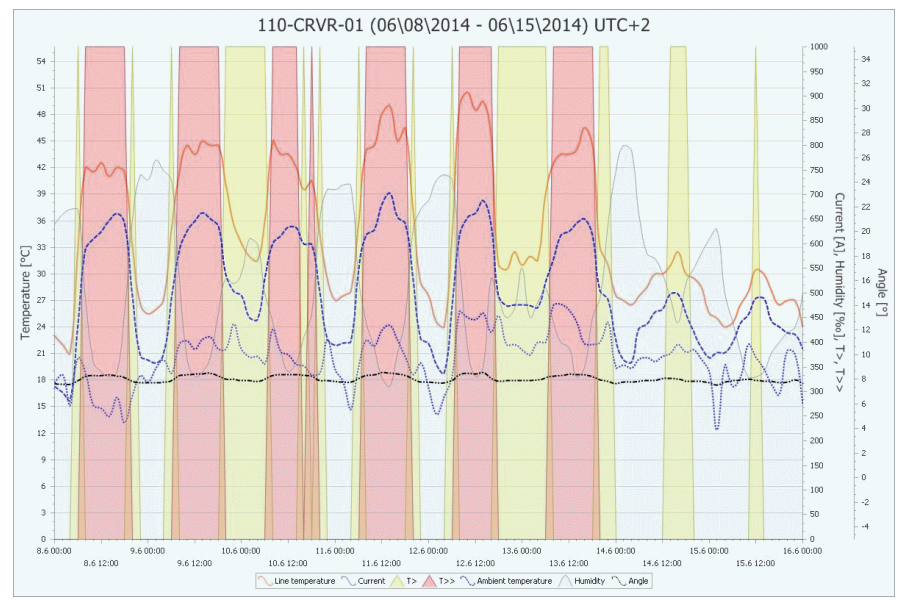

Fig. 9 Red alarms on OHL (above $40^{\circ} \mathrm{C}$ )

\subsection{OTLM - SAG}

After the catastrophic icing in Slovenia in February 2014, we started our research on the inclinometer usage, which is built in the OTLM device on OHL 2x110kV Dravograd - Slovenj Gradec, span SM23 - SM24. We carefully prepared a development project, based on the sag monitoring method, which calculated the horizontal force in the conductor at the fixing point, according to a mathematical model based on continuous measurements of conductor temperature with the OTLM device. The model was developed as a computer application, which includes installation conditions and conductor characteristics and determines the interdependence between conductor sag and horizontal force for individual temperatures. The computer application is an integral part of OTLM software. The catenary represents a starting condition for monitoring conductor behaviour on the span between two towers. Influences of ambient conditions and the electrical line current cause changes in conductor length, and consequently, change in catenary geometry. The purpose of the conductor sag measurements in the span between two towers SM23 and SM24 is to:

- Determine conductor's sag geometry for the present temperature load of the conductor,

- Determine accuracy of sag and horizontal force measurement, carried out with a computer software, 


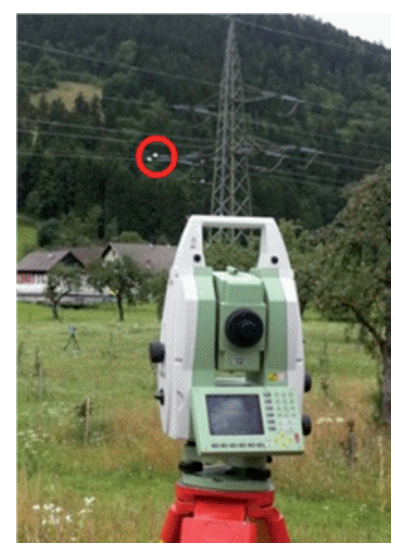

Fig. 10 Measuring station LEICA TS30 (OTLM devices are encircled in yellow)

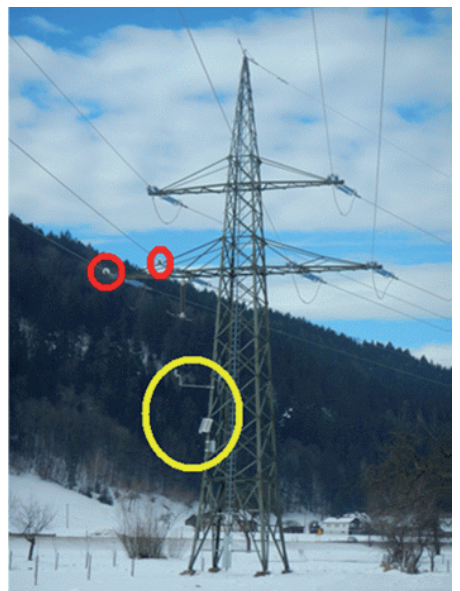

Fig. 11 Tower SM 23 with two OTLM devices (red) and weather station (yellow)

- Determine calibration parameters for the computer application based on the measured sag points at different temperatures,

- Estimate the accuracy of the angle measurement with an inclinometer, which is built-in the OTLM device.

The developed mathematical model includes mechanical and physical characteristics of the conductor, conductor weight and sag size for the calculation of internal forces.

The accuracy of the calculation is checked with an independent comparison of the calculated angle and the angle measured with the OTLM device, which is also stored in the OTLM Software. Catenary form on the span between two towers at certain temperature represents the endpoint for the computer application. Since the catenary form changes with different temperatures and metrological conditions, calculations must be made at three different temperatures. This enables us to estimate the change in catenary form in a wider temperature range. The catenary form is determined with optical-laser sag measurements on three different conductor temperatures or current loads while monitoring other ambient conditions in the field (Fig. 10).

Based on these measurements, a calibration curve was developed between the sag/angle/temperature/tensile force in

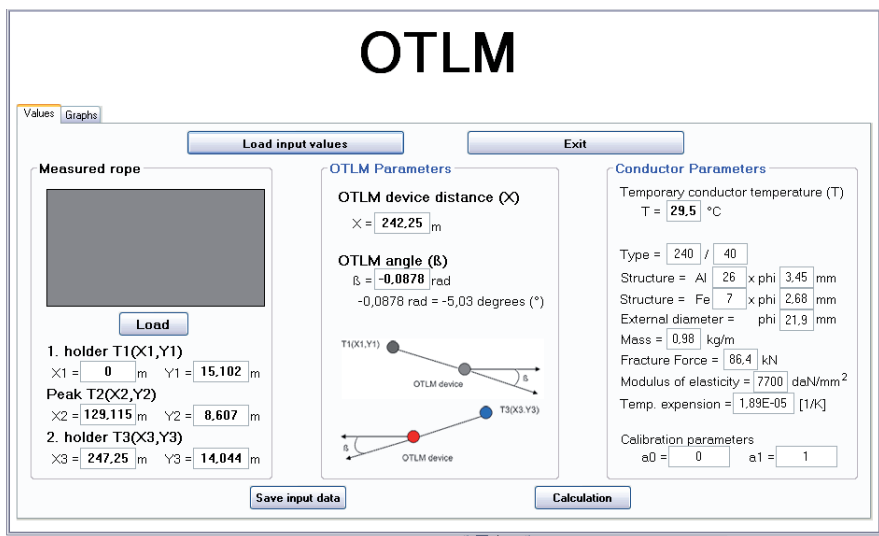

Fig. 12 Entering input data for points $T_{1}, T_{2}$ and $T_{3}$, based on measurements from 9.7.2014

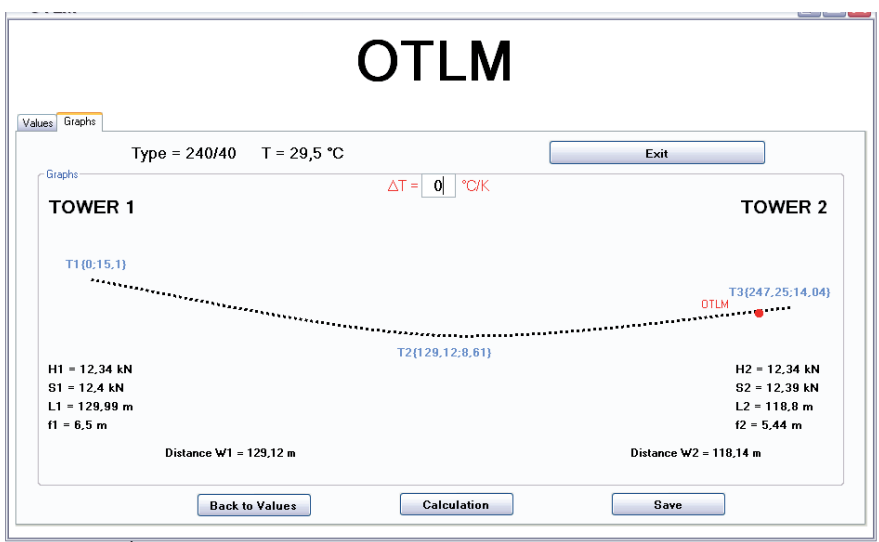

Fig. 13 Calculated forces on the conductor fixing point at measurement temperature $\mathrm{T}=+29.5^{\circ} \mathrm{C}$ and ambient temperature $+17.39^{\circ} \mathrm{C}$ (measurements from 9.7.2014)

the OHL conductor, which applies to normal working conditions or operational load [6].

If deviations from the calibration curve change in normal ambient conditions, it is possible to evaluate the occurrence of additional extra load ratings on the observed span. The mentioned application offers the user real-time monitoring and control over safe operation of the chosen OHL with different alarm state levels (i.e. alarm for icing). The influence of ambient and conductor temperature, which determines the conductor sag area, was also analysed [6].

Combining measurements of conductor geometry and sag at three different conductor temperatures with software, it is possible to calibrate the sag and angle function in its dependence from conductor temperature and evaluate the level of measurement and calculation conformity. Ensuring conformity is crucial for the implementation of the function ICING ALARM, since a continued growth of discrepancy between the measured and calculated angle in ambient conditions (ambient temperatures $-5+/-3^{\circ} \mathrm{C}$ rain and wind) is a sign of icing on the conductor.

Figure 12 and 13 show the input data for measurements on 9.7.2014 and the measured forces on the conductor fixing point at measurement temperature $\mathrm{T}=+29.5^{\circ} \mathrm{C}$ and ambient temperature $+17.39^{\circ} \mathrm{C}$. 
The numerous measurements carried out in the field have confirmed and excellent correlation between measured sags in the field and the sags that were determined with a mathematical model "OTLM-SAG", which confirms that the data can be used as an alarm when the critical sag or safety height are reached.

\section{Conclusion}

Temperature monitoring is definitely a tool that improves OHL operation in many aspects. Case studies show various uses for temperature monitoring in OHL operation and its benefits for OHL operation, such as:

- More accurate depiction of OHLs,

- Ampacity and sag evaluations,

- Optimisation of OHLs,

- Alerts in emergency conditions,

- Predicting real-time ampacity of OHLs (used together with ambient forecast),

- OHL up-rating, and

- Support to operators in managing dynamical changes on OHLs that have connected renewable energy sources (e.g. wind).

Based on experience with temperature and sag measurement supported by mathematic model of sag calculation it is now possible to calculate ampacity of the OHLs and alert operator when sag/ temperature conditions approach limits which can violate safety standards or harm conductor characteristics. Even more, based on same experience, additional load on OHLs conductors is recognised in case of icing, heavy winds or even fallen tree. This gives operator better chances to fight severe conditions. DTR of OHLs is the next step of our research which shall give operator reliable information about possible future development of sag/ temperature conditions of conductor under predicted ambient and load conditions.

\section{References}

[1] Lesjak, S., Lovrenčič, V., Dimović, Z., Mekhanoshin, B., Borodin, A., Shkaptsov, V., Salnikov, A. "Overhead line uprating using ALS and real time monitoring of conductor temperature." In: $15^{\text {th }}$ International Symposium on High Voltage Engineering (IHS). Ljubljana, Aug. 27-31. 2007.

[2] Lovrenčič, V., Gabrovšek, M. "Temperature monitoring of overhead lines (OHLs) is Smart Grid solution for power grid." In: Conference on Smart Grids 2010. Sibiu, Nov. 21-23. 2010.

[3] Lovrenčič, V., Gabrovšek, M., Marinšek, M., Polak, M. "Conductor temperature monitoring in the Slovenian transmission network." In: Transmission \& Distribution Europe 2010. Amsterdam, Mar. 29-31. 2010.

[4] Kovač, M., Lovrenčič, V., Kozjek, D., Krevelj, M. "Statično in dinamično določanje obremenjenosti DV 2x110 kV Slovenj Gradec - Dravograd na podlagi spremljanja točkovne in vzdolžne meritve temperature." (Static and dynamic load rating for OHL 2x110 kV Slovenj Gradec - Dravograd, determined with spot and whole line temperature measurements). In: $11^{\text {th }}$ Slovenian Power Engineering Conference CIGRE - CIRED. Laško, May 27-29. 2013.
[5] Lovrenčić, V., Marinšek, M., Kozjek, D., Kovač, M., Gabrovšek, M. "Točkasto i uzdužno mjerenje temperature osnova za statičko i dinamičko određivanje opterećenja DV 2x110 kV Slovenj Gradec - Dravograd." (Spot and longitudinal temperature measurements base for static and dynamic thermal rating of OHL 2x110 kV Slovenj Gradec - Dravograd). In: 11 th Conference HRO-CIGRE. Cavtat, Nov. 10-13. 2013.

[6] Lovrenčič, V., Gubeljak, N., Banić, B., Ivec, A., Kozjek, D., Jarc, M. "Monitoring za posredno određivanje promjene horizontalne sile u zavisnosti od promjene temperature i nagiba nadzemnog voda dalekovoda prijenosnog sustava." (On-line monitoring for direct determination of horizontal forces vs. temperature and incline angle of transmission conductor, Fourth session of Cired Croatian National Committee). In: $11^{\text {th }}$ Symposium on power system management HRO-CIGRE. Opatija, Nov. 10-12. 2014.

[7] CIGRE, TB 601 "Guide for Thermal Rating Calculations of Overhead Lines." Working group B2.43. 2014.

[8] CIGRE, TB 207 "Thermal behaviour of overhead conductors." Working group 22.12. 2002.

[9] CIGRE, TB 244 "Conductors for the uprating of overhead lines." 2004.

[10] CIGRE, TB 299 "Guide for selection of ambient parameters for bare overhead conductor ratings." Working group B2.12. 2006.

[11] CIGRE, TB 324 "Sag-Tension Calculation Methods for Overhead Lines." Task Force B2.12.3. 2007.

[12] CIGRE, TB 498 "Guide for Application of Direct Real-Time Monitoring Systems." WG B2.36. 2012.

[13] IEC TR3 1597:1995 "Overhead electrical conductors - Calculation methods for stranded bare conductors." 1995.

[14] "IEEE Standard for Calculating the Current-Temperature Relationship of Bare Overhead Conductors." In: IEEE Std 738-1993., 1993.

DOI: 10.1109/IEEESTD.1993.120365

[15] "IEEE Standard for Calculating the Current-Temperature of Bare Overhead Conductors." In: IEEE Std 738-2006 (Revision of IEEE Std 7381993). pp. c1-59, Jan. 30 2007. DOI: 10.1109/IEEESTD.2007.301349

[16] "IEEE Standard for Calculating the Current-Temperature Relationship of Bare Overhead Conductors." In: IEEE Std 738-2011. 2011.

[17] Mandić, N., Tenđera, T., Valentić, V. "Utjecaj vjetroelektrana na sigurnost i vođenje." (The influence of wind power plants on safety and management). In: 9th Symposium on power system management HROCIGRE. Zadar. Oct. 8, 2010.

[18] Mandić, N. "Utjecaj, VE vrataruša na sigurnost i vođenje elektroenergetskog sustava." (The influence of wind power plants on safety and management of power systems). EGE. 1/2011. pp. 102-106. 2011. 